\title{
Prof. Manuel Fernández
}

\author{
Dr. CLAUDIO NAVARRETE G. ${ }^{1}$ \\ 1 Clínica Alemana. \\ Santiago, Chile.
}

\section{Tribute to Prof. Manuel Fernández}

Sean mis primeras palabras de agradecimiento para la Sociedad de Cirujanos de Chile, que a través de su directorio, me ha distinguido con el honor de hacer la presentación del Prof. Manuel Fernández Puente como Maestro de la Cirugía chilena. Agradezco a todos ustedes y especialmente a los Profesores acá presentes, a los cirujanos y sus familiares, a los familiares y amigos del Prof. Fernández, porque son Uds. los que dan el ambiente de solemnidad, alegría y amistad que esta ceremonia merece.

El Dr. Fernández nace muy cerca de la Puerta de Alcalá en el famoso barrio madrileño de Salamanca, un 27 de diciembre del año 1933. Sus padres, don Manuel Fernández Melero, industrial, profesor de Artes Gráficas en la Escuela de Oficios de Madrid y doña Remedios Puente Muñoz, hija de un prestigioso notario de esa ciudad. Manuel ingresa a los 6 años (1939) al colegio de "Los Areneros", perteneciente a la Compañía de Jesús, hoy transformada en la conocida Universidad de Comillas. A los 12 años, la familia se traslada a Bogotá, Colombia, continuando sus estudios secundarios en el colegio de San Bartolomé, también perteneciente a la Compañía de Jesús; recibe el título de Bachiller a los 16 años (1949). Durante la permanencia en Bogotá de cinco años, se crea una sólida amistad entre los padres de Manuel y el representante de la Embajada chilena, don Julio Barrenechea, diplomático, político y poeta (Premio Nacional de Literatura año 1960), dando como resultado el traslado de la familia a Santiago de Chile, lugar de residencia definitiva. Ingresa a la Escuela de Medicina de la Universidad de Chile (1951), recibiendo el título de médico a los 25 años (1958).

Siendo alumno de 3er año de medicina, comienza su aprendizaje en cirugía, ingresando como ayudante adhonorem en el Instituto de Cirugía Experimental dirigido por el Profesor Adolfo Escobar Pacheco, donde adquiere una importante experiencia en todos los proyectos. Durante su larga estada en el Instituto, además de la cirugía digestiva, dio los primeros pasos en cirugía cardíaca, posteriormente esta práctica le permitió presentar su tesis de Licenciatura titulada “Comunicación Inter Auricular y su Corrección Quirúrgica”. Este trabajo fue premiado por la Sociedad de Cirujanos de Chile con el "David Benavente”, al mejor trabajo experimental del año 1974.

El Dr. Manuel Fernández Puente, ingresó a la carrera académica al día siguiente de recibir el título de médico (1958), como ayudante adhonorem en la Cátedra "D” de Cirugía, cuyo Director era también el Profesor Adolfo Escobar Pacheco, quien sin duda fue su principal Maestro. Mediante concursos y exámenes a través del tiempo, recorrió toda la carrera académica, hasta ser reconocido como Profesor Titular en 1978 a los 45 años de edad, después de 19 años de actividad profesional y académica.

Además ejerció los cargos de:

- Sub Jefe Servicio de Cirugía Hospital San Borja (1975).

- Jefe de Servicio de Cirugía Hospital Paula Jaraquemada (1980-1988).

- Secretario del Dpto. Médico Quirúrgico Área Central Escuela de Medicina (1973-1979).

- Sub-Director Académico Hospital Clínico Universidad de Chile (1991-1996).

- Jefe de Equipo Digestivo en Departamento de Cirugía Hospital Clínico U. De Chile (1997-2009).

El Dr. Fernández practica la cirugía de urgencia en la Asistencia Pública y sus cuatro Postas anexas. La cirugía electiva la realiza en el Hospital San Borja y Paula Jaraquemada y en clínicas de la capital.

Ello le permitió conocer la realidad quirúrgica del país, como etapa previa para perfeccionarse en el exterior. Opta por una beca de cirugía en Europa a través de la Fundación Jiménez Díaz (1965-1966); 
participó con cirujanos especialistas de renombre, tales como los Drs. Carlos González Bueno, Carlos González Moreno (Madrid); los Drs. Llaurado, Trias, Puch La Calle, en el Hospital San Pablo y La Santa Cruz de Barcelona; Mallet-Guy (Lyon), Hepp, Mercadier en el Hospital de la Pitié y Clínica Americana (París); Jordan en Arles. A su retorno a Chile, después de 1 año de perfeccionamiento, el Dr. Fernández actualiza en el medio quirúrgico nacional algunos aspectos de la cirugía digestiva, especialmente a lo que se refiere al tema de las vías biliares como la "Reparación de las Iatrogenias biliares”, llegando a juntar la casuística individual más numerosa publicada en la literatura quirúrgica, experiencia solicitada para revistas internacionales y nacionales. Promueve con énfasis la colangiografía intraoperatoria, como el mejor tratamiento para evitar la coledocolitiasis residual. Introduce el método de extracción percutánea de litiasis residual, haciendo la mayor experiencia hasta la llegada de la endoscopia. Sin duda estos aspectos hicieron avanzar significativamente la cirugía chilena. Otro aspecto fundamental en el perfeccionamiento del Dr. Fernández, ha sido la adquisición del método de investigación permanente, lo que dio base a 130 trabajos de investigación publicados durante su ejercicio profesional, además de su permanente actividad en Cursos, Jornadas, Talleres, Mesas Redondas, Conferencias; ya sea organizando o participando en 250 programas realizados.

Son destacables los cursos prácticos a través del Internacional College of Surgeons realizados en Ecuador, Perú, Argentina y Colombia, operando pacientes complejos. Participa activamente en Sociedades Científicas, como Cirujanos de Chile, Internacional College of Surgeons, Sociedades Argentina, Española, Francesa y otras de Latinoamérica.

A los 16 años de ejercicio profesional, mediante examen práctico teórico, obtiene el título de "Licenciado en Medicina y Cirugía”, el 7 de Julio de 1974, otorgado por la Universidad Complutense de Madrid, requisito indispensable para optar a un cargo de Jefe de Clínica en el futuro Hospital de la Paz en Madrid. Hoy es un Centro de Salud de nivel mundial.

El Dr. Fernández ha tenido una permanente participación en Comisiones en o por la Facultad de Medicina (90), en diversas actividades de la Universidad de Chile (1983-2009), en la Comisión Nacional de Certificación Médica (1983-2010). Finalmente, mencionaremos algunos de los premios o distinciones otorgados durante su carrera profesional; David Benavente (1975); Ernesto Prado Tagle (1963); Miembro Honorario Sociedad Argentina de Cirugía (1977); Miembro Honorario Congreso de Cirugía de Urgencia Argentino; Miembro Honorario Asociación Cuyana de Cirugía (1986); Miembro Ho- norario Asociación de Cirugía de Córdoba (1987); Ricardo Gunter Sociedad de Cirujanos de Chile (1986); Ilustre Visitante en Curso de Cirugía Cochabamba (1986); Huésped de Honor de la Ciudad de Cochabamba (1988); Presidente de la Sociedad de Cirujanos de Chile (1992); Miembro Honorario Sociedad de Cirujanos de Chile (1993); Miembro del Consejo Directivo del Decano (1994). Presidente del International College of Surgeons (1998-2010).

Se casa con la señora María Gloria Mc Kendrick Bastien (1960), con quien tiene 3 hijos: Juan Manuel, María Gloria y Valentín; a los 50 años de matrimonio la familia ha crecido con once lindos nietos. Seguramente por condiciones genéticas y por ese entorno dado por su familia, lo recuerdo como una persona feliz, como alguien que ha disfrutado lo que ha hecho en su vida, exigente pero simpático, amistoso, con muchas anécdotas, buen amigo. No es sólo conocimiento y técnica. Probablemente esa disposición es lo que lo lleva al éxito en lo que hace.

Prof. Fernández, sus condiciones quirúrgicas son conocidas y quedan más que claras al ver su trayectoria. Quiero decir que tuve la suerte de conocerlo como alumno de medicina, después fui su becado, ahora su colega y con mucho honor su amigo. Como su alumno lo recuerdo especialmente por su interés para enseñar y no sólo su interés, sino el de estimular, fomentar y exigir que en el Departamento y Servicio de Cirugía que Ud. dirigió se hiciera docencia, se cumpliera con las reuniones, que los alumnos y becados tuviéramos oportunidades para aprender todos los días. La distinción que hoy le quiere entregar la Sociedad de Cirujanos de Chile es el reconocimiento máximo a que puede aspirar un cirujano. En el mundo actual, en el que pareciera ser que lo único importante es el dinero $\mathrm{y}$ el poder, encontrar personas que dedican parte importante de su vida a enseñar, o sea a compartir sus conocimientos, es algo muy esperanzador. En el nombre de todos los que hemos sido sus discípulos quiero hacerle este regalo, es un regalo simbólico. En este libro Stephen Hawking explica las teorías más importantes de la física y la astronomía, se llama A Hombro de Gigantes y tiene ese nombre para recordar la siguiente frase de Isaac Newton: si he logrado ver más lejos es porque he subido a hombros de gigantes. Haciendo un reconocimiento a los que fueron sus maestros, a los que le dieron las bases para desarrollar su propio conocimiento, cada uno de nosotros reconoce a los que han sido sus maestros o sus hombros de gigantes. Cuando un nombre se repite para muchos de los miembros de una Sociedad, merece ser reconocido como Maestro de esa Sociedad, por eso hoy le pedimos a Ud. Prof. Fernández que acepte este nombramiento de maestro de la Cirugía Chilena. 


\section{Palabras del nuevo Maestro: Dr. Manuel Fernández P.}

Cuando la Dra. Jamile Camacho me comunicó que el Directorio de la Sociedad de Cirujanos acordó designarme Maestro de la Cirugía Chilena me sorprendió porque no soy merecedor a ello, pero también me llenó de orgullo sentirme poseedor de esta magna distinción.

El primer pensamiento fue revisar el significado de Maestro, derivado del latín magíster, que se le aplica a una persona a la que se le reconoce una habilidad extraordinaria en una determinada área del saber, con capacidad de enseñar y compartir sus conocimientos con otras personas, denominadas discípulos o aprendices.

Después me vino a la memoria un recuento sobre cuáles virtudes podrían haberme permitido acceder a tal designación.

De mis padres: Por el permanente empeño en la educación, su ejemplo de dedicación al trabajo sin límites, siempre programando planes quinquenales, sacando el máximo rendimiento a la labor cotidiana, con objetivos concretos que constituían verdaderos proyectos. Todo lo anterior motivado por una personalidad equilibrada, que no se derrumbó ante tantas contingencias que ocurrieron en la vida, ni se exaltaron orgullosamente en exceso ante los éxitos. Mis padres supieron tener valor para seguir adelante frente a las adversidades y sensatez y prudencia para recibir el tiempo y la consecución de las metas propuestas. Me inculcaron cómo, a través de estas cualidades, acompañadas de amor, trabajo, conocimientos y fe muchas veces se conseguía lo proyectado. Esta manera de proceder me dio un gran respaldo, no sólo como médico sino también como hombre, esposo, padre y amigo.

De la educación escolar: Otro pilar importante en mi formación. A los seis años (1939), me ingresaron en el colegio "Los Areneros” de Madrid, manejado por los padres jesuitas, cuya máxima rezaba "Entramos para aprender, salimos para servir"; bajo esta norma de Ignacio de Loyola permanecí durante diez años hasta recibirme de Bachiller en el Colegio de San Bartolomé Bogota (1949). En estos diez años capté el objetivo principal y la razón de ser de la educación Ignaciana, el crecimiento global de mi persona; es decir, la opción y el compromiso con los valores de acuerdo con los principios de visión humana y cristiana de la vida. Aprendí que Educar es, además de trasmitir conocimientos, también es posibilitar una experiencia personal, creando aptitudes que generen acciones capaz de trabajar para otros, tratando de realizarse para llegar a vivir en pos de los demás.

De la Universidad de Chile: Fue la Facultad de Medicina, en el Instituto de Cirugía Experimental, dirigido por el Prof. Adolfo Escobar Pacheco, donde se me acogió con afecto, se me enseñó con dedicación, aprendí el método científico, que me acompañó toda mi carrera docente, hasta llegar a Prof. Titular a los 45 años (1978). Permítanme rendirle un homenaje en estos momentos tan gratos para nosotros.

De mi esposa: María Gloria viene de un hogar cuyo padre (John), británico, y madre (Lucía), de origen francés, donde se cultivó el sentido de la responsabilidad, orden, respeto y amabilidad. María Gloria supo con maestría desempeñarse como esposa y madre, permitiendo que su marido se dedicara a la profesión, investigación, sociedades, congresos y salidas al extranjero, sin resentir mayormente la educación de los hijos. Quiero destacar con enorme alegría que estamos de $50^{\circ}$ aniversario de matrimonio. Permítanme compartir esta distinción con mi querida esposa. En nuestro caso se podría agregar aquello de que “detrás de un pequeño hombre hay una gran mujer”.

De la Sociedad de Cirujanos: El lugar por excelencia de los encuentros de los cirujanos, donde se intercambian ideas y experiencias; iniciamos un recorrido desde Secretario Anual (1972), durante 20 años, pasando por todos los cargos y comisiones, terminando con el respectivo Congreso LXV Nacional Chileno y Las Primeras Jornadas Chileno Españolas de Cirugía (1992), cuyo marco de inauguración fue en el Congreso Nacional (Valparaíso).

De mis compañeros de trabajo: Una de las experiencias más formadoras fue la de ser Profesor y Jefe de Servicio de Cirugía del Hospital Paula Jaraquemada. Ahí logramos una organización con un grupo humano que pudo sentir los mismos objetivos de trabajo, imbuido del calor humano que exige la vinculación entre profesionales, pacientes y alumnos. Todo ello fue posible mediante ética, responsabilidad y dedicación al trabajo de mis compañeros. Drs. Sergio Apablaza, Olga Andrade, Carlos Benavides, Guillermo Bannura, Jaime Contreras, Sergio Cova- 
cevich, Santiago y Jorge Cornejo, Patricio Rubilar, Alicia Young, Wiston Chinchón, Bernardo Kopman, Jorge León, Emilio Villalón, Ana María Pacheco, Rodolfo Larenas, Claudio Navarrete. Todos son activos partícipes de este premio. Gracias.
Termino agradeciendo al Dr. Claudio Navarrete por sus sentidas palabras, lo conozco como estudiante, luego formándose a nuestro lado como cirujano y después ayudándole a introducir una nueva tecnología en nuestro medio. 